\title{
The relationship between the features of figurative and logical thinking and learning difficulties
}

\author{
Alla Belousova ${ }^{1, *}$, Namjil Yamanova ${ }^{1}$, and Tatiana Sinchenko ${ }^{2}$ \\ ${ }^{1}$ Don State Technical University, Gagarin sq, 1, Rostov- on-Don, 344003, Russia \\ ${ }^{2}$ South Russian Humanitarian Institute, Krasnoarmeyskaya str., 108, 344082 Rostov- on-Don, Russia
}

\begin{abstract}
The article examines the relationship between the level of formation of verbal and logical operations and learning difficulties in primary school children. Thinking is considered as a key component of the cognitive development of the student's personality. The study sample consisted of 71 primary school children aged 7 to 12 years, including 55 boys and 16 girls. The research methods were the survey method, diagnostic methods, and statistical methods. According to the results of the study, the levels of imaginative and logical thinking and learning difficulties in younger schoolchildren are identified, and their interrelationships are highlighted. The conclusions can be used in pedagogical practice for effective psychological and pedagogical support and training of children with special educational needs in general education schools.
\end{abstract}

\section{Introduction}

The problems of digitalization of modern education exacerbate and expose the problems that have accumulated and been raised within the framework of traditional forms of education. The forced universal transition to distance learning has raised problems: educational technologies [1-2], the attitude of students to digital forms of learning [3], the psychological qualities of teachers [4], the correspondence of the image of the world of parents, teachers and students [5]. A separate issue is the search for means to improve the effectiveness of educational activities of students, in particular, the use of figurative means, proverbs and sayings in teaching in various disciplines [6], which generally corresponds to the general trends in the development of visualization and imagitiveness in education [7]. The new problems only increase the difficulties that the educational practice caused for some of the students. Problems associated with the formation of thinking characteristics begin already in preschoolers [8], but they also remain in children who come to school [9]. According to H. Uzunboylu and G. Akçamete [9], who analyzed publications on the problems of education for people with special educational needs, the terms "teaching" and "computer learning" were the most frequently used keywords in articles from the Scopus database.

\footnotetext{
*Corresponding author: belousovaak@gmail.com
} 
It is known that human cognition of the surrounding world begins with the interpretation of information coming from sensations, perceptions, being the basis for the formation of ideas, images, and thinking. In psychology, there are several approaches to the definition of thinking, on the one hand, the authors emphasize that thinking is a generalized and indirect reflection of reality, and on the other hand, thinking is the cognitive activity of a person [10]. Solso defines thinking as a process by which a new mental representation is formed through the transformation of information, and that thinking is an internal process of manipulating knowledge, combining past memories with current information, aimed at solving a problem or task [11]. In most definitions, thinking is considered as a mental process (AV. Brushlinsky, S.L. Rubinstein), as a mental activity of a person (V.E. Klochko, O.K. Tihomirov) [10], as an open self-organizing system in which thinking is aimed at determining the supersensible qualities of objects (A. K. Belousova, V.E. Klochko, O.M. Krasnoryadtseva) [12].

In accordance with the views of $\mathrm{Zh}$. Piaget, the formation of the child's thinking goes through certain stages, culminating in the stage of formal operations. At the same time, this development is a spontaneous process, not directly related to the influence of learning [13]. L.S. Vygotsky emphasizes that the development of conceptual thinking is of a social nature: interaction with other people, adults, carriers of culture and knowledge, using various psychological tools, affects the formation of generalization, the child's understanding of meanings and meanings. Studying the formation of scientific and everyday concepts, L.S. Vygotsky showed that the assimilation of scientific concepts begins at school age with the help of an adult and is aimed at the formation of freedom in their operation. According to L.S. Vygotsky, the formation of a scientific concept goes from arbitrary operation to involuntary use. Conscious learning of new concepts becomes a source of development of already established concepts: with the assimilation of a new word, the process of concept formation only begins, since the younger student must develop awareness. Vygotsky believes that the concept acquires awareness and arbitrariness in the system of already established concepts that are hierarchized in humans. Thus, in accordance with the ideas of L.S. Vygotsky, the concepts are characterized by the following properties: consistency, awareness, and productivity [14].

The basic principles of L.S. Vygotsky: from the social to the individual, from the interpsychic to the intrapsychic, from the external to the internal [14] - are reflected in the understanding of the mechanisms of thinking in the systems of P.Ya. Galperin [10], V.V. Davydov [15]. And in this case, the formation of a concept is presented as the process of entering a new term into the system of concepts, awareness and arbitrary use of it, behind which there is an understanding of the meaning and meaning of this concept.

As follows from the works of L.S. Vygotsky, V.V. Davydov, and J. Piaget, the primary school age is sensitive to the development of thinking, because it represents the age of intensive intellectual development. According to L. S. Vygotsky [14], intelligence mediates the development of mental functions, the intellectualization of all mental processes, their awareness and arbitrariness. The processes of perception, memory, imagination, speech and thinking develop due to the curiosity of the younger student, the manifestation of interest in learning about the world around them, the assimilation of new experiences, including through trial and error. According to N.N. Poddyakov, in primary school age, the transition from visual-figurative thinking to verbal-logical thinking is completed, individual differences in thinking are manifested [10]. As shown by V.V. Davidov, in the course of training, the foundations of theoretical thinking are developed, scientific concepts are formed, thinking acquires an abstract and generalized character in the course of educational activity [15-16].

In the process of studying in the primary general education programs, young schoolchildren face a number of difficulties in performing intellectual operations or mental 
actions. For many children, the sound-letter analysis of words, the definition of letters into deaf, soft and sonorous, the concepts of magnitude and quantity are very difficult. Such facts are described by P.Ya. Galperin, V.V. Davydov and this is due to the fact that younger schoolchildren still think like "in preschool age" [15].

The mental activity of primary school children as a whole is a complex interaction and interrelation of various forms of thinking. During the transition of external actions for solving mental problems to the internal plan, there is an intensive assimilation of concepts and improvement of various logical operations. The acquisition of new knowledge by obtaining a result through various operations, as well as the assimilation of new operations, is the result of the development process [16].

If a student has learning difficulties, it is necessary to identify the causes and determine the features of his development and individual capabilities in order to determine the directions of correctional and developmental work.

In our opinion, for the psychology of education, the activity side of thinking is important, which consists in the active processing of existing and new knowledge obtained in the process of solving problems and tasks. In this sense, thinking is an activity aimed at setting and achieving mental goals that are performed by a person in the process of implementing mental actions and operations [10]. Therefore, one of the psychological and pedagogical conditions for the development of thinking is the formation of skills to work with information, its understanding, transformation, thereby the formation of general educational skills, methods of activity [17].

The purpose of our study was to study the peculiarities of thinking of primary school children with learning difficulties. We proceeded from the assumptions: primary school students with different levels of imaginative-logical thinking may have different features of the manifestation of learning difficulties; difficulties in processing visual-spatial information may be associated with the features of imaginative-logical thinking.

\section{Materials and Methods}

The study sample consisted of 71 primary school children aged 7 to 12 years, including 55 boys (age $\mathrm{M}=8.6 ; \mathrm{SD}=1.2$; frequency $77.5 \%$ and 16 girls (age $\mathrm{M}=8.8 ; \mathrm{SD}=0.9$; frequency $22.5 \%)$. The respondents are students of secondary schools in Elista $(n=67 \%)$ and the Republic of Kalmykia ( $\mathrm{n}=67 \%$ ). The class distribution is as follows - students of class 1 make up 29.6\%, class 2-28.1\%, Class 3-25.3\%, and Class $4-17 \%$. The sample thus includes equivalent groups by gender, age, class, and place of residence.

The methodological tools are presented by the following methods. To study the possibility of establishing a causal relationship and spatial-temporal relationships, to analyze the child's speech development, the method "Exclusion of objects (The fourth extra)" was used in the modification of N.L. Belopolskaya: the psychologist evaluates the quality of the decision, whether a simple choice of an extra object is made, whether this choice is explained by a random set of features in the three combined objects, their functional or essential properties, and whether the corresponding verbal category is used to indicate the choice [18]. To study various intellectual operations that diagnose learning difficulties, the following methods were used: to diagnose differentiation processes, the "Seguin Board" method was used [19]; to identify the preservation of the counting skill, the stability of attention, as well as the degree of difficulty of intellectual processes, the "Counting" method was used, counting from 20 (or from 10) to 2 [19]; to understand logical and grammatical relations, vocabulary volume and speech perception, tests were used to study speech functions: assessment of spontaneous speech in dialogue and when describing pictures, tests for naming 12-14 (depending on age) subject images, tests for understanding (correlation with a picture) logical-grammatical constructions [20]; to 
identify difficulties in programming control and serial organization - program retention, a test for reciprocal hand coordination was used [20]; to identify difficulties in processing auditory and kinesthetic information-written functions, a method of examining the writing of first-grade students was used using tests to identify the skills of writing printed letters, writing words under dictation, writing sentences under dictation, copying words [21]; To identify the difficulties of processing visual-spatial and visual information-constructive praxis, the "Koos Cubes" technique was used [19].

Methods of mathematical statistics were used: descriptive statistics, Mann Whitney Utest, Spearman rank correlation coefficient. The analysis of the results was carried out using a computer program for statistical data processing "SPSS 23.0 for Windows".

\section{Results and Discussion}

The data obtained by the method "Exclusion of objects (Fourth excess)" in the modification of N.L. Belopolskaya showed that the following results are observed in the empirical group. The" high " level of task completion is observed in $7.05 \%$ : there are practically no difficulties in completing this task. In the course of completing tasks in all series, participants demonstrated a full-fledged generalization, combining subjects according to essential features. A high level of logical explanations of their decision in speech terms was recorded, the results are presented in Table 1.

Table 1. Features of thinking operations in groups with different levels of task completion

\begin{tabular}{|c|c|c|c|c|c|c|}
\hline \multirow[t]{2}{*}{$\begin{array}{l}\text { Levels } \\
\text { Completing the task }\end{array}$} & \multicolumn{2}{|c|}{$\begin{array}{l}\text { Differentiation } \\
\text { "Seguin board" }\end{array}$} & \multicolumn{2}{|c|}{$\begin{array}{l}\text { Logical operations } \\
\text { - "Counting" }\end{array}$} & \multicolumn{2}{|c|}{$\begin{array}{l}\text { Speech justification }-" \\
\text { Study of speech } \\
\text { functions» }\end{array}$} \\
\hline & $M$ & $S D$ & $M$ & $S D$ & $M$ & $S D$ \\
\hline $\operatorname{High}(7,05 \%)$ & 3.4 & 0.54 & 3.20 & 0.44 & 3.0 & 1.0 \\
\hline $\begin{array}{l}\text { Above average" }(25,35 \\
\%)\end{array}$ & 2.88 & 0.58 & 2.11 & 0.96 & 2.83 & 0.51 \\
\hline Average $(56,34 \%)$ & 2.15 & 0.53 & 1.62 & 0.70 & 2.05 & 1.17 \\
\hline Low $(11,26 \%)$ & 1.0 & 0.0 & 0.87 & 0.35 & 1.37 & 0.74 \\
\hline
\end{tabular}

The level of "above average" was found in $25.35 \%$ of the surveyed primary school students. In the process of completing tasks, the respondents of this group demonstrated the correctness of selecting an "extra" object, and could logically explain their choice in speech terms using generalizing concepts (Table 1). Difficulties mainly arose when performing tasks that were complex compared to generalizations with two possible solutions to tasks that were aimed at a higher level of abstraction from concepts.

The "average" level of task completion was found in $56.34 \%$ of primary school students. In this group of respondents, the level of conceptual development corresponds to the lower limit of the norm. Note that in this group, the unevenness of the generalizations made was revealed: when the speech justification of their choice was present, the answers of a "lower" conceptual level were present; in most cases, when comparing generalizations, the correct answers were demonstrated on a visual level, but the logic of the choice of the answer was not always verbally justified.

$11.26 \%$ of primary school students showed a " low " level of task completion. The children in this group had great difficulty explaining their answers due to their limited knowledge of generalizing words. The plan of generalizations of the respondents in this group was mainly visual in nature, in the process of speech justification of the choice, situational generalizations were observed, which is typical for thinking with elements of specificity in view of the supposed significant lack of formation of conceptual development. 
The analysis of the results shows that there are significant differences $(U=306,000$, $\mathrm{p}=0.048$ ) in the difficulty of processing visual-spatial information (a test to identify constructive praxis) in schoolchildren (boys and girls) with different levels of figurativelogical thinking.

Thus, in primary school boys with a high level of cognitive thinking, the average level of difficulty in programming control and serial organization prevails-program retention and difficulties in processing auditory and kinesthetic information - written functions. Girls with a high level of imaginative and logical thinking have pronounced difficulties associated with the processing of auditory and kinesthetic information - written functions. At the same time, a low level of verbal and logical thinking is manifested against the background of a sufficiently good level of control programming and serial organizationprogram retention.

To test the hypothesis about the relationship of verbal and logical thinking with the indicators of learning difficulties, a correlation analysis was performed using the Spearman rank correlation coefficient. The results of the correlation analysis showed stable relationships.

Table 2. Significant correlations between imaginative and logical thinking and indicators of learning difficulties trials

\begin{tabular}{|l|l|l|}
\hline & $\begin{array}{l}\text { Imaginative-logical } \\
\text { thinking }\end{array}$ & $\begin{array}{l}\text { Significance } \\
\text { level }\end{array}$ \\
\hline $\begin{array}{l}\text { Difficulties in programming control and serial organization- } \\
\text { program retention ("Reciprocal coordination") }\end{array}$ & $0.277^{*}$ & $\mathrm{p}=0.019$ \\
\hline $\begin{array}{l}\text { Difficulties in processing auditory and kinesthetic information- } \\
\text { written functions }\end{array}$ & $0.607^{* *}$ & $\mathrm{p}=0.000$ \\
\hline $\begin{array}{l}\text { Difficulties in processing visual-spatial and visual information- } \\
\text { constructive praxis ("Koos Cubes" technique») }\end{array}$ & $0.320^{*}$ & $\mathrm{p}=0.007$ \\
\hline
\end{tabular}

The results of the correlation analysis allow us to conclude that there are positive relationships (the correlation is significant at the level of 0.019) between the level of verbal and logical thinking and difficulties in programming control and serial organizationprogram retention. Such phenomena are discussed and analyzed in their work [22]. There is also a positive stable relationship (the correlation is significant at the level of 0.001 ) between the level of verbal and logical thinking and the difficulties of processing auditory and kinesthetic information-written functions. The interrelationships of verbal-logical thinking (the correlation is significant at the level of 0.007 ) and the peculiarities of processing visual-spatial and visual information were also found-constructive praxis and programming of control and serial organization-program retention. That is, the higher the level of verbal-logical thinking, the better the processing of information into written functions is carried out, the better the process of the constructive praxis function and the retention of the program. The results obtained are consistent with the studies [23].

\section{Conclusions}

1. Summing up, we can summarize the features of verbal and logical thinking with different learning difficulties. In primary school children, verbal and logical thinking is not sufficiently formed in terms of the process of speech justification and logical operations.

2. The found relationships allow us to speak about the conjugation of the indicators of verbal and logical thinking and learning difficulties. 
3. The results of the study can be used in the preparation of programs of correctional and developmental classes for younger schoolchildren who have learning difficulties.

4. Thus, the obtained data suggest that the low level of formation of verbal and logical generalization operations in young schoolchildren with learning difficulties is compensated through the development of indicators of figurative and logical thinking, through the gradual formation of conceptual thinking, through the development of the processes of analysis, comparison and synthesis.

\section{References}

1. N. Efremova, O. Shapovalova, A. Huseynova, Innovative technologies for the formation and competencies and skills assessment XXI century. E3S Web of Conferences, ITSE-2020, 210 (2020) DOI: 10.1051/e3sconf/202021018021

2. O. Fedotova, E. Platonova, V. Latun, I. Filkevich, O. Igumnov, Experience of using distance technology to teach Chinese undergraduates during the COVID-19 pandemic. E3S Web of Conferences, ITSE-2020, 210 (2020) DOI: 10.1051/e3sconf/202021022019

3. I. Abakumova, G. Zvezdina, A. Grishina, E. Zvezdina, E. Dyakova, University students' attitude to distance learning in situation of uncertainty. E3S Web of Conferences, ITSE-2020, 210 (2020) https://doi.org/10.1051/e3sconf/202021018017

4. A. Korochentseva, E. Suroedova, N. Khachaturyan, O. Nikolenko, Pupil's representation about the socio-psychological qualities of teachers in the process of effective meaning transmission. SHS Web of Conferences, 70 (2019) https://doi.org/10.1051/shsconf/20197008020

5. V. Pishchik, Indicators Of Children'S World Images And Different Generations Parents With Peculiar Relationships. Procedia - Social and Behavioral Sciences, 60, 461-468 (2018). doi: org/10.15405/epsbs.2018.07.60

6. A.K. Belousova, N.K. Epritskaya, Improving the teaching of foreign languages through comparative analysis of images in proverbs and sayings. Integration of Education 22(4), 750-765 (2018) DOI: 10.15507/1991-9468.093.022.201804.750-765

7. E.A. Makarova, E.L. Makarova, Education process visualization in metacognition development and sustainability. International Journal of Cognitive Research in Science, Engineering and Education, 5(2), 65-74 (2017) https://doi.org/10.5937/IJCRSEE1702065A

8. A. Belousova, M. Muratova, Characteristics of Visual Active Thinking of Preschoolers with General Speech Underdevelopment. Procedia - Social and Behavioral Sciences. Third Annual International Conference «Early Childhood Care and Education», 146, 196-202 (2014)

9. H. Uzunboylu, G. Akçamete, A content and citation analysis of the studies on learning environments and special education, International Journal of Cognitive Research in Science, Engineering and Education (IJCRSEE), 8(2), 95-104 (2020) doi: 10.5937/IJCRSEE2002095U

10. O.K. Tikhomirov, Psychology of thinking, Academy (Moscow, 2002)

11. R.L. Solso, O.H. MacLin, M.K. MacLin, Cognitive Psychology. 8nd edn. Pearson Education Limited (Harlow, 2007)

12. V.E. Klochko, E.V. Galazhinsky, Self-realization of personality: a systemic view (Tomsk University Publishing House, Tomsk, 1999)

13. J. Piaget, The Psychology of Intelligence (Taylor \& Francis Ltd, London, 2001) 
14. L.S. Vygotsky, Human developmental psychology (Smysl, Eksmo, Moscow, 2005)

15. V.V. Davydov, Types of generalization in teaching (Pedagogical Society of Russia, Moscow, 2001)

16. V.V. Davydov, Developmental learning theory (INTOR, Moscow, 1996)

17. N.M. Vostrikova, The concept of "thinking" in psychological and pedagogical literature. Siberian Pedagogical Journal, 8, 255-259 (2012)

18. N.L. Belopolskaya, Exclusion of objects (Fourth extra): Modified psychodiagnostic technique: Guide for use (Kogito-Center, Moscow, 2009)

19. S.Ya. Rubinstein, Experimental methods of pathopsychology and experience of their application in the clinic (Publishing house of the Institute of Psychotherapy, Moscow, 2010)

20. Zh.M. Glozman, A.Yu. Potanina, A.E. Soboleva, Neuropsychological diagnostics in preschool age (Peter, St. Petersburg, 2006)

21. T.V. Akhtina, O.B. Inshakova, Neuropsychological diagnostics, examination of writing and reading of primary schoolchildren (Moscow, 2008)

22. N.A. Khokhlov, M.S. Kovyazina, A.N. Cherkasova, N.R. Salikhyanova, Test for reciprocal hand coordination: approbation of a quantitative modification of the method. Psychology, 6, 141-149 (2016)

23. O.L. Lukash, Features of the processing of kinesthetic and auditory information in primary school children. Scientific-theoretical journal "Scientific notes", 82(12), 101 $106(2011)$ 